\title{
A brief history of the evolution of ASM Annual Meetings
}

\author{
Robert M. Timm* and Suzanne B. McLaren \\ Department of Ecology \& Evolutionary Biology and Biodiversity Institute, University of Kansas, Lawrence, KS 66045, USA (RMT) \\ Section of Mammals, Edward O'Neil Research Center, Carnegie Museum of Natural History, Pittsburgh, PA 15206, USA (SBM)
}

*Correspondent: btimm@ku.edu

The original bylaws of the American Society of Mammalogists (ASM) state that the Society's objectives are "the promotion of the interests of mammalogy by holding meetings, issuing a serial or other publications, aiding research, and engaging such activities as may be deemed expedient" (Journal of Mammalogy 1919 (1):49). Now celebrating its 100th anniversary, the Society has continued to hold Annual Meetings and they have evolved considerably over the years. As part of the 75th anniversary volume, Gill and Wozencraft (1994) provided the first overall history of the Annual Meetings of ASM, noting an increase in conservation- and genetics-related presentations, in ecology and behavior papers, and an increase in presentations by female biologists over the years. In their informative and well-documented review of the Annual Meetings from 1919 to 2000, Genoways and Freeman (2001) detailed the changes and expansion of the presentations and the increasing role of women at the meetings, concluding that possibly the "most important function of the Annual Meeting has been the intangible building of esprit de corps among members of the Society ...[which] led to a sense of mammalogical community, joint research among members, promotion of young mammalogists, the championing of conservation issues ... and the building of a financially strong Society ...." Herein, we expand on some aspects of this rich history and explore recent significant changes to the meetings.

Hartley H. T. Jackson is credited by first and long-time ASM Historian Donald F. Hoffmeister with much of the organizational efforts and hard work required to make the Society and first meeting possible in April of 1919 (Hoffmeister 1994). At the organizational meeting of the Society in 1918, "voluntary contributions of $\$ 2.00$ from persons in the Washington area" were requested as a funding base (Hoffmeister 1994 (1):ii). On 3 April 1919, the newly formed Society met at the National Museum of Natural History with 54 members in attendance; the annual dues were set at $\$ 3$, a value of approximately $\$ 45.68$ in 2019.

Annual Meetings have been scheduled every year since 1919, with three exceptions. During World War II, gasoline rationing and the involvement of many Society members in the war effort limited participation. As a result, the meeting to be hosted at the Carnegie Museum in Pittsburgh was canceled and only eight Officers and Directors met in 1943 to conduct Society business at the National Museum of Natural History in Washington, D.C. In 1944, the Officers, Directors, and 27 members met at the American Museum of Natural History in New York City for a single day (see Genoways and Freeman 2001) but no papers were presented and no committee reports were given. In 1945, again, the Officers and Directors only met for one day at the Chicago Museum of Natural History (now Field Museum of Natural History) to conduct essential Society business (Hoffmeister 1969). The traditional Annual Meeting was resumed in 1946, with the Carnegie Museum hosting the long-delayed event that had first been planned for 1943. Caroline A. Heppenstall served as the organizer and co-host of the meeting (Fig. 1). During WW II, a number of women served in the workforce, including as curators in U.S. museums. When soldiers returned from the war, some of those interested in mammals went to graduate schools on the GI bill, and many then, upon graduation, took positions at universities, colleges, and museums with the rapid growth of the U.S. education system. Most of those positions went to men.

Over the years, the Society has undertaken a number of different experiments with its meeting venues and the way the meetings are conducted to increase the scientific content, interest in the meetings, and appeal to a broader audience, especially students and educators. All but four meetings have been held in the U.S. (one in Mexico: Mexico City, 1964; three in Canada: Toronto, 1948; Winnipeg, 1965; Vancouver, 1971). Historically, members based on university campuses or at large museums with mammal research collections hosted most meetings. However, meeting sites have varied, including a shortlived attempt to regularly schedule meetings at "out-of-doors" locations with eight meetings held in national parks, vacation sites, and conference centers (Fig. 2; Hoffmeister 1969; Genoways and Freeman 2001). Beginning in 1974, a plan was initiated for rotating meeting sites among five geographic

(C) 2019 American Society of Mammalogists, www.mammalogy.org 


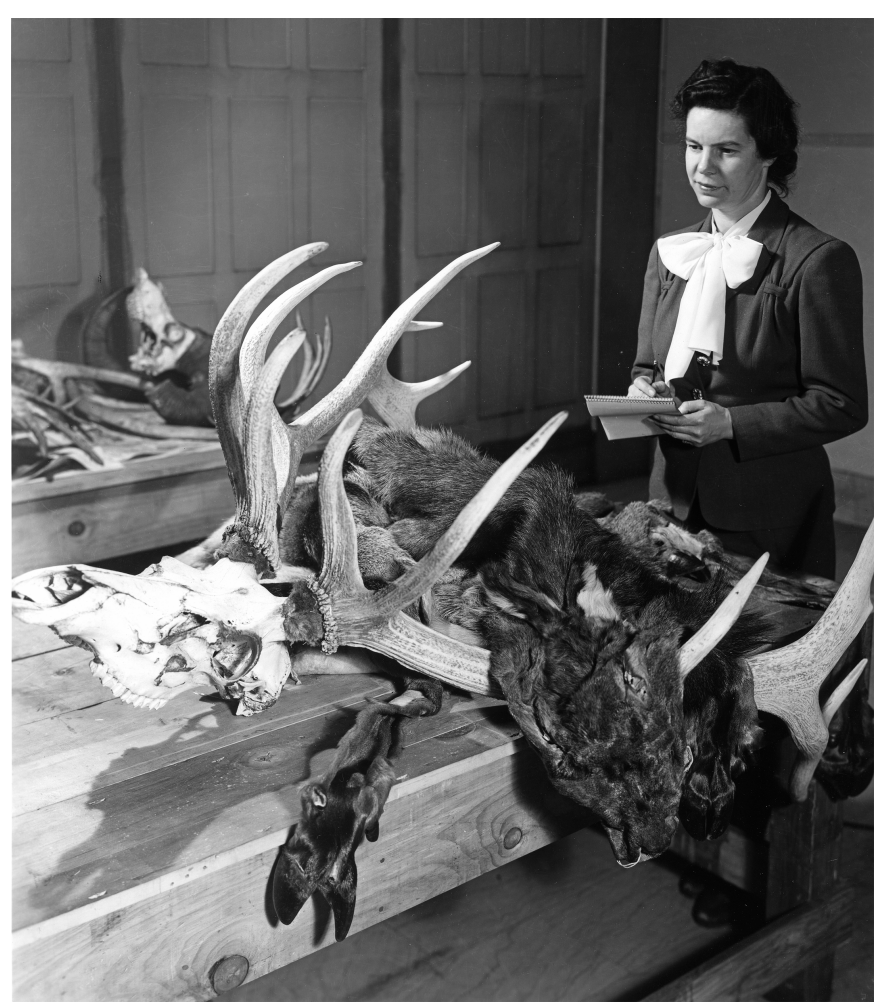

Fig. 1.-Caroline A. Heppenstall (b. 1912; d. 1991), known to her friends as Heppie, was the first woman to serve as the primary organizer and co-chair of a Local Committee when the 1946 Annual Meeting of the American Society of Mammalogists was in Pittsburgh at the Carnegie Museum. She is shown here collecting data from an elk at the museum in 1945. Heppie retired from the Carnegie Museum as Associate Curator of Mammals (1938-1977). Photograph courtesy of the Carnegie Museum of Natural History Photo Archives.

regions to ensure that members would be able to regularly attend a meeting near them, depending on the availability of local hosts (Genoways and Freeman 2001; see a map of regions and upcoming meeting dates on the ASM Program Committee website: www.mammmalogy.org/committees/program). Members at the Annual Meeting vote on the venue of a future meeting two years in advance. At the 1981 Annual Meeting, the traditional show of hands failed to determine which invitation would be accepted. A written ballot followed this, but again ended in a tie. The decision to meet at the University of Florida in 1983 was ultimately "based on the flip of a coin" (Journal of Mammalogy 62:870); the coin was then donated to the ASM Historian for inclusion in the Society archives at the Smithsonian.

In keeping with the Society's usual two-year advance planning for meeting sites, a partnership was developed in 2011 with the Department of Continuing Education at Kansas State University, Manhattan, Kansas, which later became Kansas State University's Conference Services. Using those services, the Society conducted four meetings at convention centers-Reno, Nevada (2012; Fig. 3); Philadelphia, Pennsylvania (2013); Norman, Oklahoma (2014); and Jacksonville, Florida (2015) — in an experiment to assess whether convention centers provided greater convenience, ease of planning, and lower cost. Members determined that they preferred the more traditional venues, and a return to the campus-style meeting occurred in Minneapolis, Minnesota (2016), Moscow, Idaho (2017), and Kansas State University, Manhattan (2018). The 75th and 100th Annual Meetings were held in Washington, D.C., the site of the ASM's first Annual Meeting and long-term home base of the Society because of the leadership provided by the mammalogists housed at the Smithsonian Institution.

The standard oral presentations at the meetings have evolved considerably over the decades. For much of the early history of the meetings, papers were "read." Presentations were eventually supplemented with the use of overhead projector images. When $2 \times 2$ color slides and Kodak carousel projectors became available in the mid-1960s, they became a critical component of presentations. As slide carousels became commonplace, it also presented an opportunity for a few pranksters to insert an unexpected slide into a speaker's carousel unbeknownst to the speaker. Usually these were relatively harmless; for example, a surreptitiously placed image of copulating elephants or an elephant mounting a rhino was enough to shock the speaker and create levity in the audience. There have been many light moments over the years when speakers came up with witty rejoinders during an awkward moment.

Beginning in the late 1990s, PowerPoint slideshows replaced the standard photographic slides and carousel, as it did throughout academia. Electronic presentations allowed a speaker to make corrections and alterations to a presentation right up to, and including, the day of the talk. One of the most memorable presentations was given during the 2004 Annual Meeting at Humboldt State University. As the Program Committee was assembling the abstracts for talks, a notable title caught their attention: "Behavioral evidence and physical finds in support of the unverified primate hypothesis for Sasquatch.” Because the abstract suggested that this was going to be a serious talk on the search for Sasquatch, the decision as to whether it should be accepted was passed to the Officers. It was debated whether to include the talk in the program, and the decision was made that it is not our place to pre-judge someone's science, but rather provide an open forum for discussion; the talk was allowed to proceed. The talk proved to be a serious presentation on efforts to document the presence of Sasquatch in the Pacific Northwest, but despite the researchers' diligent field efforts, their cameras and recording gear failed every time they were close to documenting the presence of Sasquatch. Unfortunately, only a few blurry images have ever been recorded of this most elusive North American creature. Unlike some scientific societies, the ASM has never chosen to evaluate abstracts for acceptance, or limit the program to only a select number of presentations.

Poster sessions were first introduced in 1979 with a single session of 15 poster presentations. At the 2019 meetings, 144 posters were presented at two poster sessions. Evening poster sessions with libations and hors d'oeuvres are always especially well attended. Beginning in 2003, a high-profile speaker of broad interest was added as a Capstone, in part to encourage participants not to depart the meetings early. 


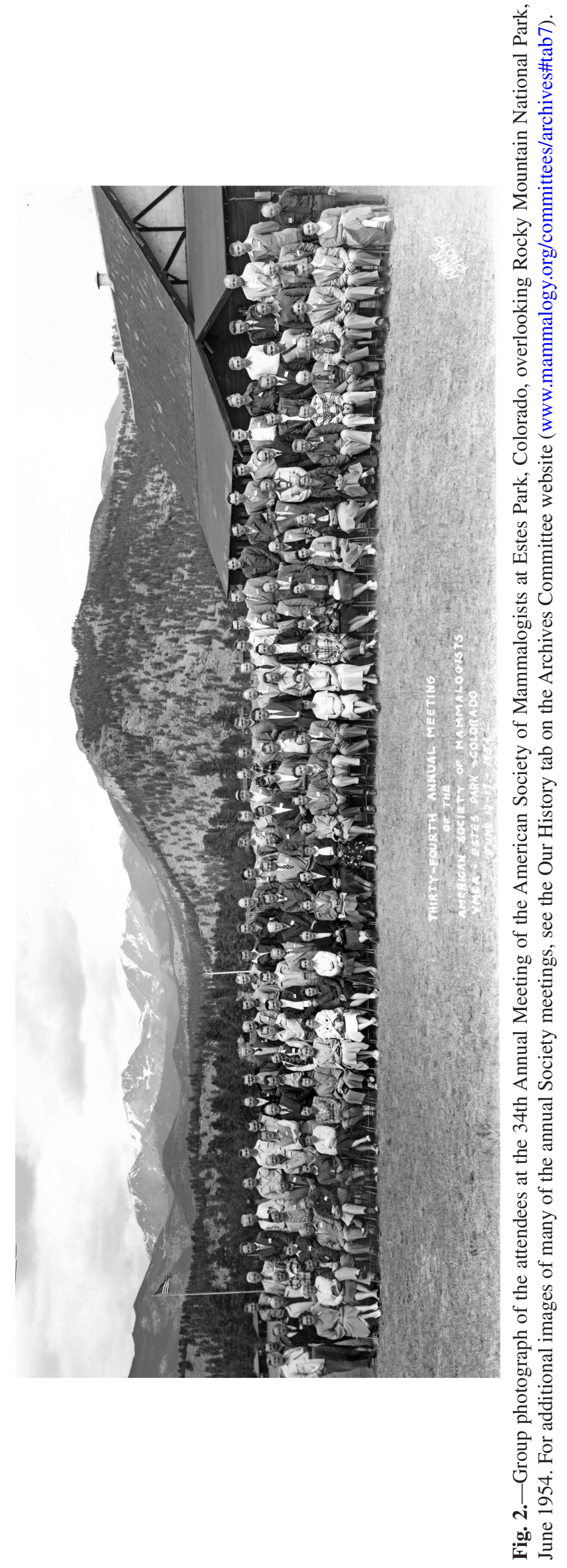




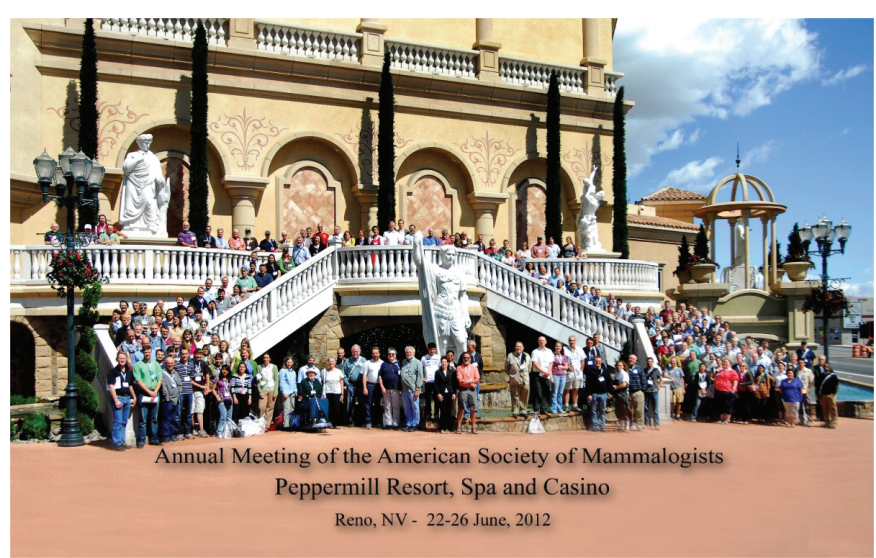

Fig. 3.-Group photograph of the attendees of the 92nd Annual Meeting of the American Society of Mammalogists in Reno, Nevada, June 2012.

In recent years, a number of innovations were introduced to the Annual Meetings, including pre-meeting workshops and additional funds provided as travel grants to students (in the 2020 budget some $\$ 150,000$ was provided for student travel and research awards).

Beginning in 2013, the Informatics Committee led the effort to establish a smartphone app for the Annual Meeting through a freely available platform called EventBase. This allowed attendees to view the program and abstracts, and tag presentations and social activities as well as the time and place of committee meetings, thus setting a personalized agenda. In 2016, an upgraded version of the meeting app, called Guidebook, was provided by the University of Minnesota, and the Informatics and Program committees worked together to upload meeting information. The use of a meeting app has gained popularity with each meeting and positive feedback has signaled the desire of attendees to have such access going forward.

Another digital development is the use of social media. Members can tap into platforms such as Facebook (https://www. facebook.com/American.Society.of.Mammalogists), Twitter (@Mammalogists), and Instagram (@amersocmammalogists) for regular updates and news during the meetings. Members of the Informatics Committee report information about each speaker during the Plenary Sessions, supplemented with photographs obtained during each presentation. New awards are conveyed to social media in real time, so that someone who cannot attend an Annual Meeting still can enjoy the camaraderie of the activities that we all anticipate. Input from other participants keeps this reporting lively and provides a feeling of spontaneity.

Electronic copies of committee reports have replaced hundreds of printed copies of those reports that historically were carried to each meeting by committee chairs, shared during Board Meetings and Members' Meetings and, subsequently, carried home by so many members. While the Society had traditionally mailed a copy of the program of the Annual Meeting to every ASM member for decades, the program and abstracts are now offered as a PDF; a few printed copies can be pre-ordered and picked up at the meeting for a fee. This is not merely a moneysaving initiative, but reduces our carbon footprint as well.
Through the 1970s and early 1980s, evenings were often times for unstructured but libations-fueled socials. Donations were collected that went to purchase beer. Beginning in the 1970s, one evening included an auction. Over time, this evolved into a well-attended fundraising event that encompassed the interactive social activities that have always been enjoyed at the auction but with a better grade of items for sale and the proceeds going to support student research. Over the last five years, a "Silent Auction" was added. The items are all donated, and the money collected supports our Future Mammalogists Fund. In the mid-2010s, auctions typically generated $\$ 6,000-\$ 7,000$. Many senior members use the auction as a mechanism to make a donation to the Fund by adding to their winning bid when they reach the sales table.

For many years a formal banquet was part of the meetings, often held on the evening prior to the last day of sessionsmen wore suits and ties, and women dressed formally (Fig. 4). During the 1970s and 1980s, the price of the meetings' registration, the banquet, and the picnic inevitably increased, and at the same time student attendance also increased. Unfortunately, the overall cost of the meetings became a hardship for many younger members. The net result was that younger members often had to trim expenses, and the banquet was an obvious target-it was a formal sit-down, and for those not knowing many members, it seemed like the easiest way to economize. The picnics were a better opportunity to meet new people, to socialize, and the costs were generally more modest. An unconventional event informally called the "Alternative Banquet" was organized by Norman Slade, the Grinnell Award recipient in 2004. Norm scoped out the area pizza establishments that also served beer and arranged a pizza night on the evening of the banquet. These became so popular that they cut into the banquet attendance, and many students were torn between attending the banquet because their advisor wanted them to versus going to the fun pizza night out. At times, up to 40 individuals participated in the Alternative Banquet. As the popularity of the Alternative Banquets grew-they were fun, rowdy, and socially welcoming to all-senior members grew concerned about the declining participation in what was supposed to be an inclusive, capstone-like evening event. Because the formal banquet had served as a time to recognize awardees, rethinking the banquet was necessary. Beginning in 2015, the banquet was changed to an affordable, much less formal, and more welcoming "closing social."

Over the last few years, the Society established a Code of Conduct, which is now explicitly written into documents associated with attendance at our Annual Meetings. The Society wants to ensure that our meetings are as welcoming and safe for every member as they are scientifically rigorous and socially enjoyable.

\section{ACKNOWLEDGMENTS}

Our advisors, Elmer C. Birney and Gordon L. Kirkland, Jr., got us involved in ASM activities and attending the Annual Meetings early in our graduate careers and were most influential 


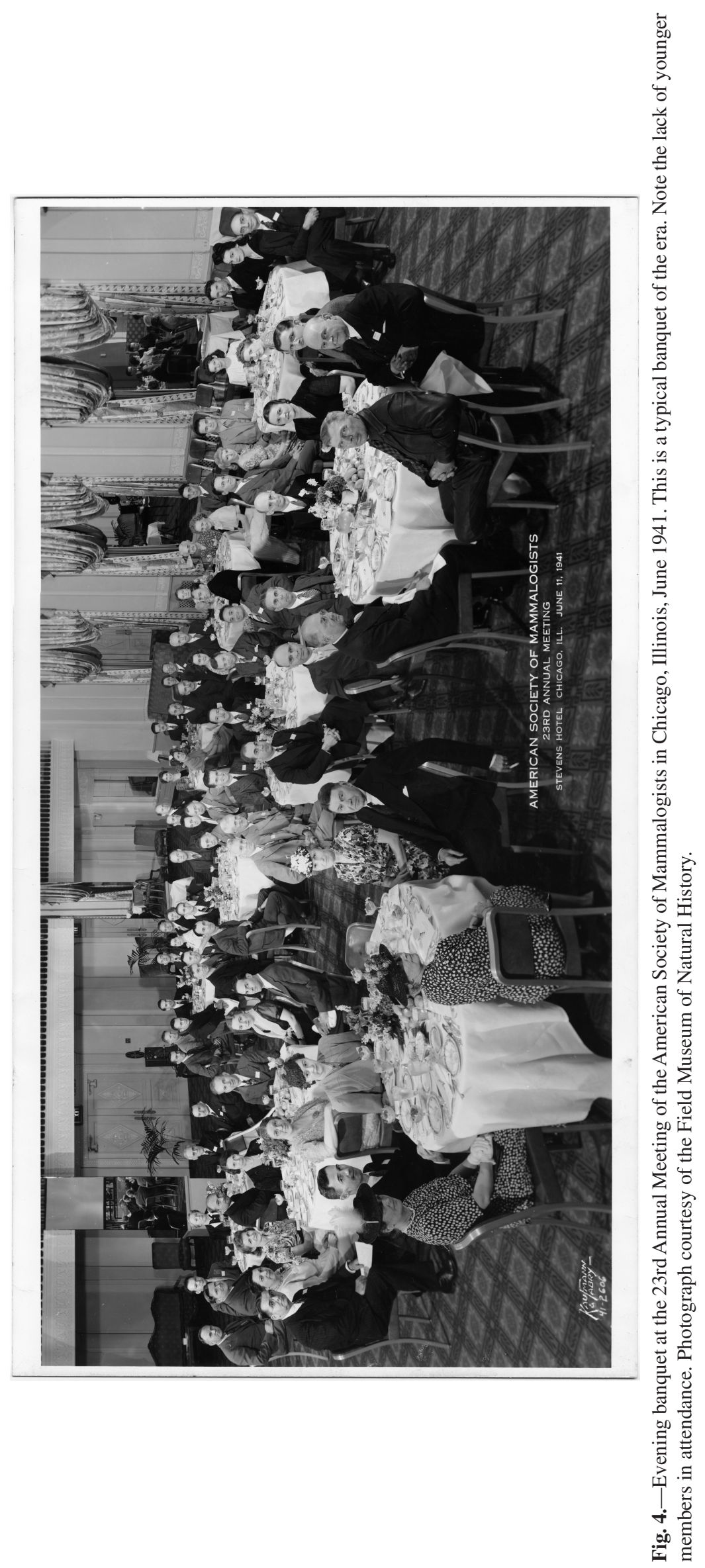


in our career paths; for that we are forever grateful. They were both avid attendees of the ASM Annual Meetings and shared that enjoyment with us. We thank H. H. Genoways, E. J. Heske, and D. A. Schlitter for sharing their insights on the rich history of the ASM with us, significantly contributing to the details presented here. Figure 4 was provided courtesy of L. R. Heaney and L. Nassef, Field Museum of Natural History, Chicago. M. G. Girard's masterful efforts in improving the figures used herein are most appreciated. We acknowledge Donald F. Hoffmeister, the ASM's first and long-time Historian (1966-1995) and Past President, for his efforts in documenting the fascinating history of our Society. Following Hoffmeister's example, throughout 2019 we attempt to provide aspects of the Society's history in the Journal to complement our 100th anniversary celebration.

\section{Literature Cited}

Genoways, H. H., AND P. W. Freeman. 2001. Evolution of a scientific meeting: eighty annual meetings of the American Society of Mammalogists, 1919-2000. Journal of Mammalogy 82:582-603.

Gill, A. E., and W. C. Wozencraft. 1994. Committees and annual meetings. Pp. 155-170 in Seventy-five years of mammalogy (1919-1994). Special Publication 11, American Society of Mammalogists, Lawrence, Kansas.

Hoffmeister, D. F. 1969. The first fifty years of the American Society of Mammalogists. Journal of Mammalogy 50:794-802.

Hoffmeister, D. F. 1994. Hartley H. T. Jackson and the American Society of Mammalogists. Journal of Mammalogy 75(1):i-ii.

Hoffmeister, D. F., AND K. B. Sterling. 1994. Origin. Pp. 1-21 in Seventy-five years of mammalogy (1919-1994). Special Publication 11, American Society of Mammalogists, Lawrence, Kansas. 